\title{
COVID-19 and a Call to Adapt Dental Education
}

\author{
Murad Alrashdi ${ }^{1 *}$, Ahmed Hameed ${ }^{2}$ and Abdullah Aljabr ${ }^{3}$ \\ 1 Department of Orthodontic and Pediatric Dentistry, College of Dentistry, Qassim University, Buraydah, Saudi Arabia, \\ ${ }^{2}$ Microbiology and Immunology Graduate, Biology Department, University of Texas, San Antonio, TX, United States, \\ ${ }^{3}$ Department of Medical Education, College of Dentistry, Majmaah University, Al Majma'ah, Saudi Arabia
}

OPEN ACCESS

Edited by:

Varinder Goyal,

Guru Nanak Dev Dental College \&

Research Institute, India

Reviewed by:

Jorge Luis Castillo,

Universidad Peruana Cayetano

Heredia, Peru

Deepti Shrivastava,

Al Jouf University, Saudi Arabia

*Correspondence:

Murad Alrashdi

mu.alrashidi@qu.edu.sa

Specialty section: This article was submitted to

Pediatric Dentistry,

a section of the journal

Frontiers in Dental Medicine

Received: 05 February 2021 Accepted: 06 April 2021

Published: 30 April 2021

Citation:

Alrashdi M, Hameed A and Aljabr A (2021) COVID-19 and a Call to Adapt

Dental Education.

Front. Dent. Med. 2:664460.

doi: 10.3389/fdmed.2021.664460
Introduction:COVID-19 has harmed the economic, academic, and clinical pursuits of dental educational institutions and dental students. As dental associations, health agencies, and regulatory bodies around the globe announced the need for social distancing and stricter safety measures, some dental schools worldwide have been adapting to accommodate for such changes.

Methods : This review attempts to provide a general picture of the early responses of some dental schools worldwide to the COVID-19 crisis and identify some of the regulations that influenced dental schools' initial decisions. An analytical approach was used to assess changes to dental school curriculums in didactic (academic/non-clinical) and clinical education, examinations, administration, and dental school research. The assessment was based on a web-based search of a variety of online global references including research articles, reviews, letters, press releases, and surveys regarding the early effect of covid-19 on dental education at some dental institutions in the U.S, Europe, and Asia from late February to early July of 2020. The review also offered further recommendations to dental school administrators regarding the future of dental education during the early stages of a pandemic.

Conclusions: Innovations in technology and blended educational methodologies will continue to influence how certain dental schools around the world adapt to the changes caused by COVID-19 and better prepare dental education institutions for potential future public health disruptions.

Clinical significance: Dental schools will need to adapt their education system to improve didactic, preclinical, clinical, administrative, and research components of dental education in response to the changes caused by COVID-19 and future pandemics.

Keywords: dental education, dental innovation, COVID-19, education technology, educational innovation

\section{INTRODUCTION}

In recent times, the spread of Severe Acute Respiratory Syndrome-CoV-2 (SARS-CoV-2) virus, the causative agent of COVID-19, has caught the attention of disease and medical experts worldwide. COVID-19 has mainly been known for causing upper respiratory tract infections with manifestations ranging from mild common cold to severe pneumonia (1). While the negative impact of COVID-19 on medical and nursing fields is quite obvious, other health fields such as dentistry are also struggling to cope with the pandemic $(2,3)$. In fact, the close proximity of dentists 
to patient's saliva, blood, body fluids, and aerosols results in a potentially high risk of transmission to dental practitioners (4). For this reason, the practice of dentistry has been classified as a very high exposure risk job due to the invasive and aerosolgenerating procedures dentists perform $(5,6)$.

Such high transmission risks have also limited the academic and clinical pursuits of some dental schools and dental students worldwide (2, 3, 7-12).

Although dental associations and health agencies in some countries offered general guidelines for use in dental settings, official recommendations for dental education institution implementation of social distancing and infection control measures while maintaining the continuity of dental education were lacking $(13,14)$. Because local and state regulations vary widely, dental schools in certain nations have been making decisions based on the regulations and recommendations provided by their localities (7, 9-12, 15-17). Therefore, the specific changes made to the way dental education is implemented and how such changes impact students and faculty also vary.

What early changes to didactic (academic) and clinical instruction methods did dental education institutions in some nations make to protect dental students from COVID19 while maintaining the continuity of dental education? What implications did these changes have on their faculty, administrators, and research activities? Such questions are being raised in order to determine how dental education in some countries may be adapted in response to future pandemics. In this review, we attempt to answer these questions by analyzing the initial responses of a select group dental institutions, dental students, and dental educators in certain countries around the globe. We will provide a general picture of some of the early regulations and responses of these dental schools during the pandemic. We will also make further suggestions for dental education administrators and faculty to help dental schools adapt to the changes caused by COVID-19 and other potential future public health disruptions.

\section{DENTAL SCHOOL CURRICULA AROUND THE GLOBE}

Dental education methodologies and curricula differ around the world. In the U.S. and Canada, students usually attend 34 years of undergraduate study to obtain a bachelor's degree before attending dental school. Dental education requires 4 years of dental school followed by another 2-3 years for more specialized training (18). Generally, the 4 year dental school curricula at North American dental schools is divided into didactic (academic) instruction in the first 2 years followed by 2 final years of clinical instruction and training (18).

In the first 2 years of didactic instruction, students attend face-to-face lectures and learn about basic and dental oriented biological sciences such as oral anatomy and physiology. In the final 2 years, students attend face-to-face clinical instruction, perform clinical rotations, and treat patients under supervision by clinical professors.
Additionally, a majority of North American dental schools require senior students to provide dental care by participating in community-based clinical treatment experiences (19). Many dental schools in North America have also adopted Problembased learning (PBL) and Case-reinforced learning (CRL) methodologies to better integrate student's theoretical and hand skills (18). In problem-based Learning, there is less emphasis on the traditional didactic lecture format. Instead, students selflearn through peer teaching and discussion of patient problems in small groups (18). Case-reinforced learning encourages students to discuss lecture applications in small group conferences via case studies $(18,19)$.

In some Asian countries like China, Malaysia, Japan, and Pakistan, dental education has a different approach. For example, dental education in China requires 5 years of undergraduate training (bachelor's degree) and 3 years of graduate training (Doctorate degree) (18). For the undergraduate training, the first 3 years are didactic in a lecture-based format, while the fourth and fifth years focus more on pre-doctoral clinical training. The 3 years of graduate training is largely clinical (18). Chinese dental education is based on a stomatological methodology, where dentistry is treated as a subspecialty of medicine. The model places an emphasis on integration of medical and dental sciences in didactic coursework $(18,20)$. Adoption of PBL learning, community-based clinical exercises, and self-learning tools have become increasingly more popular among Chinese dental schools. However, the traditional model of lecture-based instruction still remains the favored method of dental education for most didactic courses (18).

Similar to China, Malaysia has a 5 year undergraduate dental education program. In Pakistan, dental education requires 4 years of study (21). The first 2 years are focused mainly on didactic education, while the last 2 years focus more on clinical training (22). In Japan, dental education is 6 years long. The first 4 years are for didactic and lab coursework. The last 2 years involve clinical internship rotations (23). Meanwhile, in the Middle East, many dental schools require 5 years of dental education (24). However, in Saudi Arabia and Kuwait, dental schools have 6 year programs. The first 3 years tend to focus more on didactic and lab courses, while clinical rotations take place in later years (24).

In some European nations, dental education methodologies also varies. In France, dental education requires about 6-9 years of study, with initial years being dedicated to face-toface didactic (academic) instruction and later years dedicated to clinical instruction (8). In Italy, the dental education system involves 5 years on didactic and pre-clinical instruction followed by 1 year of clinical instructions and rotations (6). The UK and Ireland both have 5 year dental education programs (22).

Compared to Asian countries like Pakistan and China, North American dental education has a stronger reliance on PBL, CRL, and computer and e-based technologies, which focus more on developing self-learning skills $(18,25)$.

Although there are some procedural differences among dental schools, didactic and clinical instruction remain major components among all dental schools. Problem-based Learning, Case-reinforced Learning, and community-based clinical activities are also major components of many dental schools 
worldwide. In this review, we will assess changes to the curricula of some dental schools in regard to both didactic (academic) and clinical education components of dental education in response to COVID-19. We will also discuss other components of dental education such as examinations, administrations, and research activities.

\section{METHODS}

This review attempts to provide a general picture of the early response of some dental schools worldwide to the COVID-19 pandemic and identify some of the regulations that were influencing their decisions at the time. An analytical approach was used to assess changes to dental school curriculums in didactic (academic/non-clinical) and clinical education, examinations, administration, and dental school research activities. The assessment involved an analysis of changes that were in response to preliminary regulations that hindered the normal curricular activities of some dental schools in the U.S., Europe, and Asia.

Electronic searches were conducted from on published paper from the start of pandemic until March 2021 in PubMed, Web of Science, and Google Scholar. The assessment was based on a search of a variety of online references including research articles, reviews, letters, press releases, and surveys regarding the immediate impact of covid-19 on dental education at various dental institutions. The web-based search included references relating to the impact of covid-19 on some dental schools in the U.S., Europe, and Asia. The countries and dental schools in this review were chosen based on the available evidence obtained from the search to the research questions. Any reference that answered our research questions were included in the review.

The research questions included online searches for dental schools early changes to didactic (academic) instruction, clinical instruction, administrative, and research methods in response to the COVID-19 pandemic.

\section{RESULTS}

An online based search of the currently available literature found that some dental schools were making changes to academic and clinical procedures, administrative policies, and research activities $(6,7,9-12,14)$. The reported results covers the impact of covid-19 on dental education in the following areas: didactic (academic/non-clinical) education, clinical education, examinations, administration, and school research activities in the early stages of the pandemic.

These changes were in response to preliminary regulations that hindered the normal curricular activities of some dental schools. Such regulations were found in some countries in the U.S., Europe, and Asia (7, 9-12, 15). For instance, in Europe, governments initially mandated total lockdowns of many European dental schools where students and faculty were banned from campuses of dental institutions $(7,9,11)$. In the U.S., many dental schools were locked down in response to government and dental agency recommendations (14). In Asia, governments mandated strict social distancing measures that limited gatherings and closed schools $(6,12,25)$.

\section{DIDACTIC (ACADEMIC) EDUCATION}

Due to lockdowns and guidelines from federal, state, and local authorities to reduce the transmission of COVID-19, some North American, European, and Asian dental schools initially sent students home as they planned to evaluate curricular changes to dental education programs $(6-9,11,12,17)$. In regards to faceto-face didactic instruction, alternative models of education and evaluation, such as live and prerecorded online lectures, virtual problem-solving activities, and computer-based reports and exams, once considered insufficient, were being implemented by dental schools in response to COVID-19 $(2,6,7,9,11,12)$.

One article that discussed online symposiums about innovation of dental education during the COVID-19 pandemic involved dental educators from different countries presenting on innovations to their school's curricula during the pandemic (6). The symposiums were held from 30th March 2020 to 10th June 2020 (6). The dental educators included scholars from 8 countries and 11 dental schools in Asia. They included 2 dental schools from Taiwan, 2 dental schools from Philippines, 2 dental schools from Japan, and 1 dental school each from Malaysia, Cambodia, Thailand, Singapore, Hong Kong. They also included 3 dental schools from the USA and 1 dental school each from Australia, Canada, Italy, England, Switzerland, and Canada (6).

The presentations provided a general idea of the early changes that some countries made to didactic, clinical, and research activities during COVID-19. According to presenters at the symposium, dental schools in Australia, Cambodia, Japan, Malaysia, Thailand, Hong Kong, and the United States all reported that didactic lectures and PBL courses had initially been moved online (6). Dental schools in Taiwan did not move their didactic courses online. Due to Taiwan's success in controlling the spread of the pandemic they continued regular in-person classes (6). However, the Taiwanese dental schools did delay the start to their new semester by 2 weeks (6). In response to government directives dental schools in the United Arab Emirates (UAE) also moved all their didactic courses to online distanced learning (26).

Meanwhile in Pakistan, all teaching activities were suspended and didactic courses were moved online in response to government and health directives (25). The shift to online coursework was challenging for dental educators in Pakistan. Some common issues raised include limited access to high speed internet, faculty not being "tech-friendly," faculty lacking training with online class setups, and internet disconnections (25).

Since North American dental schools have recently moved away from the traditional didactic lecture format and encouraged self-learning through the use of e-learning tools and peer teaching methodologies such as Problembased learning (PBL) and Case-reinforced learning (CRL), adjusting the didactic curriculum to move online during COVID-19 was less challenging (18). In the U.S. online software platforms like Zoom, WebEx, and Panopto allow didactic courses to be offered as live or pre-recorded lectures 
$(8,14)$. Teaching methods that require students to go through online modules and take an online seminar assessment where comprehension of the modules are assessed through problem-based learning was recommended by one review of U.S. dental schools (14). VoiceThread and EDpuzzle were some software platforms proposed for implementing these teaching methods (14).

Similar to some U.S. dental schools, UAE dental schools employed online learning systems to post-course content, prerecorded lectures, conduct exams, organize discussions, and post-grades (26). Video conferencing technology such as Microsoft teams was used for live class presentations by instructors and students. Instructors also underwent virtual training sessions by IT support teams for the transition to distance learning (26). The IT support teams assigned technical support staff to all the instructors (26).

In regard to didactic testing, U.S. dental schools utilized assessment software such as Canvas and ExamSoft for virtual exams and quizzes. Faculty-monitored webcams and artificial intelligence programs were used to record students and report suspicious activity during exams to make sure rules were not violated. Proctoring services from third-party companies were also advised $(8,14,27,28)$.

UAE dental schools also conducted exams with webcam monitoring by faculty in addition to lockdown browsers that blocked students from opening other applications during the exam (26).

Some dental schools in Europe have also moved to online teaching by utilizing online pedagogical software tools, video streaming, online materials, and virtual meetings $(7,9,11)$. For example, one dental school in Italy delayed the spring semester to allow the school enough time to upload online content such as video lectures (7). Some European dental schools have encouraged the use of e-learning, webinars, virtual meetings, email, and software platforms like Moodle for the delivery of online curriculum content $(9,11)$. Didactic assessments and examinations were either post-poned or moved online for many European dental schools $(6,7,9,11)$. Most of the dental schools in France utilized online exams through software platform known as Moodle (9).

Chinese dental schools have also moved a majority of their didactic courses to online platforms in response to COVID19 using e-learning tools, video-conferencing, and pre-recorded video materials. To help students continue to apply their knowledge in practical situations, Chinese dental schools have increased their reliance on Problem-based Learning (PBL) (12).

How effective a shift to online didactic instruction will be in terms of limiting COVID-19 infections at dental schools while maintaining the continuity of dental education remains in question. E-learning was well-received by students and professors at one dental school in Italy and has proven effective at limiting COVID-19 infections (7). The effectiveness of the shift to online and virtual curricula at limiting the spread of COVID-19 is apparent, but its effectiveness in maintaining the continuity of dental education is less apparent. In the U.S., dental students are very much used to technology and can easily adapt (28).
However, some students may struggle to adapt from classroom settings to a lonelier online learning environment $(25,27)$. Also, the main points a professor wants students to understand in a virtual lecture can be missed and students may instead spend more time on topics that professors did not intend students to concentrate on (27). In regard to Problem-based learning, which depends on student engagement, smooth virtual interactions remain crucial. However, virtual interactions can be hindered by technical difficulties (12). In China, e-learning is seen as a temporary solution instead of a permanent replacement for traditional lecture-based teaching methods (12).

\section{CLINICAL EDUCATION}

In regard to pre-clinical laboratory simulations, face-to-face clinical instruction, clinical rotations, and patient treatment, dental schools around the world have been impacted greatly as they were forced to comply with regulations and school closures $(7,9,11,12,14,15)$. A review of online symposiums revealed that dental schools in Australia, Hong Kong, Japan, Malaysia, Philippines, Thailand, Switzerland, Pakistan, and USA initially ceased all in-person laboratory simulation courses (6, 25). In Cambodia, lab simulations were continued with virtual settings (6). In contrast, Taiwan dental schools continued regular lab simulation exercises in-person due to Taiwan's success in controlling the pandemic (6).

Clinical education for dental schools in these countries experienced similar changes. In the early stages of the pandemic dental schools in Australia, Cambodia, Hong Kong, Japan, Malaysia, Philippines, Switzerland, Thailand, USA, and Pakistan suspended all clinical activities $(6,25,26)$. The exception was again Taiwan due to their success controlling the COVID19 pandemic spread (6). Although many clinical training instructions were suspended, dental schools in Australia, Japan, Malaysia, Philippines, Switzerland, Taiwan, Thailand, USA, Pakistan, and the United Arab Emirates continued emergency treatments of patients at school dental clinics $(6,25,26)$. Meanwhile, Cambodian dental school clinics treated less patients due to PPE shortages (6). Dental schools in Hong Kong experienced a postponement of emergency treatments (6). In Taiwan, dental school clinics delayed emergency treatments by 2 weeks and added other measures including screenings and history checks to their safety protocols.

In France, dental students lost about 4 months' worth of clinical practice due to cancelation of student clinics and clinical examinations (8). For many European dental schools, clinical work was limited to emergency dental treatments performed only by senior faculty and students while non-emergency cases were rescheduled $(7,9)$. For dental students in Italy during the height of the pandemic, clinical rotation activities could not be replaced by remote activities and were delayed until the next semester (7).

Also, some European dental schools responded to school closures, social distancing mandates, and travel restrictions by creating a web-based alternative clinical examination that was followed by presentations to faculty (11). The dental schools council in the UK, which is directed by the leaders of many 
dental schools in the UK and Ireland, recommended changes to clinical education including more clinical simulations on mannequins, more PPE and safety protocols, and the extension of clinical training for students (29). In Italy, the Italian government mandated interactive learning tutorials and presentation of case reports as part of clinical training activities for dental students (7). However, virtual measures across Europe were not comprehensive since they were limited to only the few aspects of clinical education that did not require hands-on practice $(7,11)$.

In China, dental schools did not substitute teaching of clinical skills with e-learning tools as e-learning could not truly replace real hands-on practice and manual dexterity development (12). Chinese dental schools postponed clinical examinations and final year students had to attend additional months of clinical instruction before graduating (12). The same was true in Italy where online examinations were only used to assess theoretical skills, not clinical skills (6). In Europe, many schools also postponed clinical skill evaluations and extended program dates rather than lower clinical education standards for graduation $(9,11)$.

In the UAE, hands-on clinical training was postponed and dental schools offered students a compensation program for having to delay the next academic year (26). In the meantime, UAE dental schools offered some temporary pre-clinical practice exercises to students including case discussion sessions and simulated situations where students performed teleconsultations (26). Also, the schools offered preliminary clinical assessments based on clinical situations that tested students' knowledge of treatment plans and judgement of complex cases (26).

In Malaysia, initial changes to clinical education were in response to the government enforcement of the Movement Control Order (MCO) in mid-March of 2020, which ceased all clinical dental training, face-to-face instruction, and dental community outreach services (30). However, exceptions were made to final-year dental students who were required to complete clinical training (30). Malaysian government initiatives also included increased adoption of digital healthcare services for clinical dental education (30).

In the U.S., hands-on clinical activities were initially canceled as dental schools adopted new technology and virtual curriculums, school-sponsored events and travel were suspended, and necessary meetings were performed with social distancing measures to mitigate the spread of the virus $(8,13,14,17$, 31). Due to safety concerns about COVID-19, less patients were coming in for elective dental treatments at dental school clinics and community-based clinics. Since students at U.S. dental schools experienced appointment cancellations at dental school clinics they missed out on community-based clinical treatment activities (31). Therefore, dental students had less clinical work and experienced delays toward completing their clinical requirements for graduation $(3,13)$.

In response to school closures due to COVID-19, one U.S. dental association suggested the use of alternative exam models for patient-based exams and completion of licensure requirements (32). The alternative examination model assessed dental students' clinical skills without requiring them to perform procedures on a patient by using manikin-based exams (32). Such manikin-based exams have been described as modern and ethical approach to dental licensure (3). At U.S. dental schools, the initial response included a shift to virtual simulation-based OSCEd clinical exams replaced live-patients clinical exams (6). All these changes to clinical curricula will have serious implications for the continuity of dental education at dental schools. Alternatives to clinical dental education will have to be explored in order to maintain the continuity of clinical education at dental schools.

Virtual reality (VR) simulation and haptic technology has been considered as an alternative form of clinical education as it can help simulate touch and feeling of virtual tooth tissues and has the potential to improve hand-eye coordination and motor skills (8). However, VR and haptic technologies are also very costly and cannot fully replace a hands-on clinical approach with a live patient (8). This is also true for manikin-based exams (3). Although virtual education programs and manikinbased exercises may help students and faculty simulate clinical activities, it may not completely replace the quality of regular clinical education involving live patient treatments.

Furthermore, some have suggested that teledentistry, which involves remote dental guidance and treatment through the use of online platforms would work well as an alternative to inperson visits for non-emergency dental treatments. Teledentistry can also help dental schools conserve limited PPE reserves and aid in triaging of patients during screening processes $(3,33,34)$. In addition, insurance companies now offer reimbursement for teledentistry services and many state officials and boards in the U.S. have approved their use (3). However, the selection of dental treatments possible through teledentistry are limited to oral guidance since students still cannot perform hands-on treatments on live patients. Although teledentistry may be useful as an alternative to in-person visits for non-emergency dental guidance, it is not a sufficient alternative to clinical treatment.

Another key aspect of clinical dental education changes are found in oral radiology, which includes instruction in both theoretical and practical methods of image analysis and other radiographic techniques (35). Although oral radiology clinics experience less exposure to aerosol production than other dental specialties such as oral surgery and periodontics, intraoral radiographs can stimulate gag reflexes, coughing, and saliva secretion so the threat of transmission is still present among patients, students, and staff (36). Some recommendations for reducing transmission in radiology clinics called for dividing students into smaller groups, decreasing the amount of patient appointments, and appropriate social distancing between X-ray and imaging rooms that are integrated with operatory rooms (36).

Other recommendations proposed clinical curricula changes that included the preference of extraoral imaging techniques such as panoramic radiographs or cone beam computed tomography over intraoral radiographs for advanced training (36, 37). However, for schools that use intraoral radiograph training, the use of adequate PPE, double barrier imaging receptor sensors, and rinsing or oxidizing agents for patients before image taking were recommended to prevent cross-contamination $(36,37)$. The use of anthropomorphic phantoms (advanced realism manikins) for student's intraoral radiograph practice was also preferred over 
live patients (36). Further recommendation included the use of teleradiology for student clinics, which involves secure online sharing of digital images rather than physical images to minimize COVID-19 transmission risks $(36,37)$.

Right now, these alternatives may only serve as temporary or supplementary solutions to maintaining the continuity of clinical dental education. The reopening of dental school clinics may be the only way to effectively maintain the continuity of clinical dental education. However, the return to regular activities at dental school clinics will require more adequate infection control measures.

For infection control within dental school clinics, one review recommended the use of hand scaling techniques, anti-retraction handpieces, rubber dams, high-volume suction, and high efficiency particle air filtrations systems, which help minimize aerosol production during dental treatments. The review also recommended that faculty and students observe proper hand hygiene, perform antiseptic mouth rinses, and wear appropriate PPE including full-length gowns, respirators, face shields, and disposable gloves (10). Rapid COVID-19 detection test kits was also suggested as being effective for dental schools that treat a high volume of emergency cases. However, false test results can still escape such infection control measures (38). Since these measures are commonly employed as effective infection control methods in medical and clinical settings dental schools around the world readily adopted them $(7,11,12,38)$.

For instance, as lockdown restrictions were slowly rolled back by the Chinese government, Chinese dental schools resumed face-to-face and clinical teaching. The clinics operated in a limited capacity with preference given to senior students in the programs (12). Antiseptic mouth rinses, sodium hypochlorite disinfection, rubber dams, and high-volume suction were utilized in the clinics. The use of aerosol generating instruments were also limited. In addition, dental students and faculty underwent weekly COVID-19 testing (12). As normal in-person clinical education resumed, many European dental schools relied on their national guidelines for guidance on safety protocols in the clinics (10). Italian dental schools added cross-infection control to the curriculum as part of clinical training activities (7). How effective these infection control measures will be remains to be determined.

Some U.S. dental schools added screening protocols for treating emergency cases based on U.S. Centers for Disease Control (CDC) guidelines, which included the rescheduling of dental appointments for patients who were ill or who traveled to areas affected by the virus (38). One U.S. dental school reported a more thorough screening/triage process to lower the transmission risk for their emergency cases (38). This process included phone interviews to determine if a patient had any COVID-19 symptoms, positive COVID-19 tests, or reports of exposure to COVID-19. Also, pretreatment physical exams in separate rooms from the treatment room were performed with both the patient and provider wearing masks. In the treatment room, providers wore N95 respirator masks, face shields, and other PPE equipment and performed treatments using highvolume evacuator (HVE) suction and rubber dams to reduce aerosol generation during dental procedures (26).
To reduce the risk of cross-infection, treatment rooms were temporally limited to use once every $24 \mathrm{~h}$ to allow for aerosols to settle onto surfaces and make disinfection easier. Treatment rooms were then disinfected with sodium hypochlorite solution prior to use. Dental care providers were divided into teams that were temporally and socially separated. Each team provided care for 1 week, followed by 2 weeks of self-isolation to help reduce the likelihood of exposing the entire clinical department to even a single infected provider (38). The U.S. dental school that employed this method concluded that the temporal and social separation process was effective at reducing viral transmission, conserving personal protective equipment, and expanding the availability of providers (38).

The process of prioritizing of emergency dental cases, employing multiple screenings, temporally and socially spacing clinical teams, and strict infection control protocols in the treatment rooms certainly seems like an effective method for limiting the spread of COVID-19 in dental school clinics. However, some dental schools in less developed nations like Cambodia, which experienced PPE shortages and Pakistan, which lags behind in technological applications, may not have access to the same resources as the dental school in the U.S. that implemented this process $(6,25)$. Therefore, various applications of this process and further assessments will be required to determine its applicability elsewhere.

\section{ADMINISTRATION OF DENTAL EDUCATION}

Changes to dental school administration in the initial stages of the COVID-19 pandemic were also made. In the U.S., dental school administrators were required to submit reports on the "interruption of education" during COVID-19 to the Commission on Dental Accreditation $(13,27)$. The reports included all disruptions to didactic, laboratory, preclinical, and clinical parts of their education program along with a detailed plan for temporary solutions that maintain accreditation standards and the continuity of dental education $(14,39)$.

Whether or not U.S. dental schools were able to maintain such accreditation standards since the start of the COVID-19 pandemic and subsequent regulations is not yet clear. In Europe and Asia, reports regarding the ability of dental schools to maintain dental education accreditation standards during COVID-19 are even less clear. More research will be needed regarding the maintenance of dental school accreditation standards during the COVID-19 pandemic before any comprehensive analysis or further recommendations can be made. Our review only serves as a general analysis on the issue.

Regarding the administration of student, faculty, and staff well-being, dental schools were found to be lacking in adequate mental health support services (11). For instance, in Europe a significant percentage of dental schools had no mental health support services specifically in response to COVID-19. For dental schools that did have support services for students and staff, the 
services mainly included only academic contacts and emergency phone numbers (11).

No evidence was found regarding the presence of COVID-19 specific support services at U.S. and Asian dental schools during the initial stages of the pandemic. We suspect that the lack in COVID-19 specific mental health support services may be as prevalent in the U.S. and Asia as they are in Europe since reviews on the subject in the U.S. and Asia don't mention administrative changes that include mental health services. Even before the pandemic, a systematic review reported that the incidences of dental schools instituting mental health programs for students and staff were few (40). Despite the lack in adequate mental health support services, overall stress about the COVID-19 crisis, which includes fear of getting infected by the virus and anxiety about redesigned classes was common among dental students during the initial stages of the pandemic $(2,14,41)$.

\section{RESEARCH}

Due to social distancing measures and other guidelines issued by health authorities, all non-essential research activities and clinical-based dental research projects were suspended and/or delayed at dental schools around the world $(2,3,8,11,12)$. In fact, an online symposium review of many dental schools showed that regular research activities were initially canceled in Australia, Cambodia, Hong Kong, Japan, Malaysia, Philippines, Thailand, Pakistan, UAE, Switzerland, and the USA $(6,25$, 26). Due to early success in controlling the spread of the pandemic, Taiwan was the only nation found to continue with their regular research projects (6). In addition, research meetings and conferences at some schools were canceled, which impeded research presentations and collaborative efforts between institutions conducting dental research $(6,8)$.

Disruptions to dental research activities have also affected promotion and tenure decisions for clinical and adjunct faculty participating in research (8). However, some positive effects of the closure of dental school research labs may be that researchers had more time to work on publications and take advantage of new funding opportunities relating to COVID-19 and dentistry $(2,3)$. Some dental schools in the U.S. have implemented policies that give faculty members more time to complete their research activities and requirements for promotion (8). In the UAE, Microsoft teams video conferencing technology was used for graduate dissertation presentations by student researchers (26).

\section{RECOMMENDATIONS}

Based on the existing changes being made to dental education, alternatives have been either employed or discussed to help protect students, faculty, and staff and help minimize disruptions to the education of dental students. These alternatives consist of measures to help improve didactic, preclinical, clinical, administrative, research, and graduation components of dental education in response to the changes caused by COVID- 19 . Overall, dental education institutions should follow the latest guidelines and regulations offered by their national or local health authorities as they reopen since our recommendations only serve as alternatives to the early changes that were considered by the dental schools in our review.

In terms of didactic education, dental curriculum should be revised to create dental education modules that are disseminated via blended learning, which involves a mix of face-to-face traditional class learning with online virtual learning. This method will not only help reduce class sizes, but will also help those students who struggle with lonelier online learning environments by providing them with physical access to instructors. This will also help instructors engage further with students and direct their learning.

In addition, Problem-based learning (PBL) and Casereinforced learning (CRL) methods at many dental schools rely heavily on student engagement and peer-teaching. This can sometimes be lost in completely virtual learning environments due to technical difficulties. Blended learning environments will help provide more opportunities for peer-teaching and foster more direct collaboration. Therefore, dental schools should invest in the creation of an extensive blended learning program for didactic education. Also, since dental schools in Asia and Europe may lag behind the U.S. when it comes to the application of PBL, CRL, and e-learning methodologies in their curricula., blended learning methods will provide a middleground alternative between a completely virtual education method and traditional education methods.

Moreover, students and faculty should be provided with 24/7 tech support services for online learning applications. Finally, for dental schools under total lockdowns, instructors should be advised to host virtual office hours for struggling students to get more help. Office hours outside of normal virtual class times are vital for student support at certain times during the COVID-19 pandemic where only virtual education may be possible. To assess the effectiveness of these changes at the end of the semester, dental schools should provide surveys and questionnaires to students, faculty, and staff for getting feedback about any strengths or weaknesses and comparing educational results with those of previous years.

In terms of clinical education, online-based solutions cannot replace the quality of clinical education that on-site and handson training provides. Virtual simulation sessions in their current form may be only useful for teaching pre-clinical skills, but cannot fully replace a hands-on clinical approach. Therefore, simulation technologies will have to remain supplemental for now (7).

Furthermore, we advise against the use of Virtual Reality (VR) simulation and haptic technology as an alternative form of clinical education. In addition to high purchase and maintenance costs, VR and haptic technologies cannot attain the same clinical education standards that real patient practice does. However, as an alternative for teaching pre-clinical skills during COVID-19 and government-imposed lockdowns, 3D printing technology maybe a more cost-effective alternative to VR and haptic technologies.

Along with the use of manikins for pre-clinical practice, 3D printing can be deployed as an effective treatment visualization tool. 3D printing of teeth and other dental-related models can 
help students stimulate training of hands-on dental skills (42). The teaching of some 3D printing concepts to dental students has proven to be successful in one study (43). Furthermore, simulated technologies like teledentistry and $3 \mathrm{D}$ printing will help reduce crowding and time spent by students, faculty, and staff in the clinic. Therefore, due to the limitations caused by the COVID19 pandemic we recommend that dental schools invest more in $3 \mathrm{D}$ printing technology for clinical education as they have for manikins since there are numerous practical applications for it in clinical dentistry.

Thus, for clinical education we recommend a blended learning curriculum that combines teledentistry for nonemergency dental treatments requiring basic oral guidance with manikins and 3D printing technology for simulated practice plus supervised live patient treatments for hands-on clinical practice. Results of a survey of dental educator respondents from Saudi Arabia, Egypt, India, Pakistan, Germany, USA, Hong Kong, Australia, Kuwait, and Canada suggested that hybrid or blended learning curricula that combines online distant learning with virtual simulations and lab work plus traditional clinical instruction with live patients is the preferred solution moving forward (44). If not permanent changes, these alternatives can serve as temporary solutions to help dental students in clinical training progress faster during COVID-19 restrictions.

Moreover, as dental schools begin resuming clinical operations, it is important to minimize the risk of COVID19 transmission in their clinical programs. Dental schools around the world have mentioned various infection control measures to limit the spread of COVID-19. However, infection control measures are only effective if they are properly enforced.

Other than implementing sufficient infection control procedures in the clinic, some have suggested that dental schools include infection control of airborne diseases as part of their clinical curricula to strengthen compliance. We recommend that dental schools go further than that by creating an infection control department within the dental school establishment that hosts committees that regularly evaluate and regulate how infection control measures are being implemented by students and faculty. Also, some clinical staff supplied with biosafety checklists should be specially designated to enforce infection control measures in the clinic by making sure students follow all safety measures. We also propose that dental schools utilize 3D printing technologies to conserve PPE resources and help produce COVID-19 testing equipment. For example, face masks, face shields, and nasal testing swabs can be produced continuously by $3 \mathrm{D}$ printers in dental school labs.

In terms of administrative changes, we advise that dental school administrators produce or publish reports that detail how restrictions due to COVID-19 have impacted didactic and clinical parts of their programs in terms of maintaining accreditation standards. Such reports will be valuable for researchers to find solutions to issues dental schools may have with maintaining the same quality of education as they had before the pandemic. Furthermore, dental schools around the globe should move to fill a gap in mental health services for dental students, faculty, and staff to calm fear and anxiety. In regard to dental school research activities, we recommend that they be resumed albeit with similar infection control measures that we recommended for dental school clinics. Finally, dental schools should provide researchers with more incentives to find solutions to combat the negative impact of COVID-19 on dental education.

\section{LIMITATIONS}

This review has several limitations. First, the review was limited to the initial or early response of dental schools to COVID19. The results of this study may only provide a valuable historical representation of the experience of dental education programs and schools during the early stages of the pandemic and provide further insight into adapting dental education as new guidelines are being introduced. However, more comprehensive longitudinal studies may be required to fully understand all the latest changes to dental education during the prolonged stages of the pandemic and beyond.

Second, the review is limited by the group of countries from which the dental schools were chosen based on the available evidence we obtained from the search to our research questions. This includes a select group of dental schools from Asia, Europe, Australia, the middle east, and the U.S. The sample of dental schools we selected may not be representative and may also be biased toward certain regions of the world. Lastly, the recommendations in this review are limited since they present alternatives to the early changes that were being considered by the dental schools in the review. As the situation with the pandemic continues to change, recommendations and guidelines will change as well. Thus, the recommendation in this review may not apply to every nation all the time.

\section{CONCLUSION}

Our analysis of the results revealed that the impact of the COVID-19 pandemic initially affected dental education in a significant way. From early on in the pandemic, dental schools made many changes to their academic, clinical, administrative, and research policies. The systemic changes to dental education in response to COVID-19 has exposed the strengths and weaknesses of some dental school curricula around the world.

For instance, the increased reliance of dental schools worldwide on Problem-based learning (PBL) and Case-reinforced learning (CRL) methodologies has helped ease the shift of didactic dental education toward a more virtual-based curriculum. In contrast, the lack of airborne infection control curricula and alternatives to clinical education initially forced many dental school clinics to completely shut down. Although dental school curricula are based on educational delivery models that are over 50-years-old, new innovative technologies and methodologies are helping dental schools adapt to the way dental education is done during a pandemic.

Educational methodologies like blended learning and new technologies such as $3 \mathrm{D}$ printing have certain benefits for the learning process of dental education during the 
pandemic. This is reflected in the recommendations made in this review. Such innovations will continue to influence how dental schools adapt to the changes caused by COVID-19 and to better prepare dental education institutions for potential future public health disruptions.

\section{AUTHOR CONTRIBUTIONS}

MA: conceived the ideas and design the review. MA, AH, and AA: contributed to the writing, editing, and formatting of the article from the start till the end. All authors contributed to the article and approved the submitted version.

\section{REFERENCES}

1. Fallahi HR, Keyhan SO, Zandian D, Kim SG, Cheshmi B. Being a front-line dentist during the Covid-19 pandemic: a literature review. Maxillofac Plast Reconstr Surg. (2020) 42:12. doi: 10.1186/s40902-020-00256-5

2. Barabari P, Moharamzadeh K. Novel coronavirus (COVID-19) and dentistry-a comprehensive review of literature. Dent J. (2020) 8:53. doi: $10.3390 /$ dj8020053

3. Saeed SG, Bain J, Khoo E, Siqueira WL. COVID-19: finding silver linings for dental education. J Dent Educ. (2020) 84:1060-3. doi: 10.1002/jdd.12234

4. Peng X, Xu X, Li Y, Cheng L, Zhou X, Ren B. Transmission routes of 2019-nCoV and controls in dental practice. Int J Oral Sci. (2020) 12:9. doi: 10.1038/s41368-020-0075-9

5. U.S. Department of Labor OSaHA. Guidance on Preparing Workplaces for COVID-19. Washington, DC: U.S. Department of Labor OSaHA (2020)

6. Chang TY, Hong G, Paganelli C, Phantumvanit P, Chang W, Shieh YS, et al. Innovation of dental education during COVID-19 pandemic. J Dent Sci. (2021) 16:15-20. doi: 10.1016/j.jds.2020.07.011

7. Bennardo F, Buffone C, Fortunato L, Giudice A. COVID-19 is a challenge for dental education-A commentary. Eur J Dent Educ. (2020) 24:8224. doi: 10.1111/eje.12555

8. Elangovan S, Mahrous A, Marchini L. Disruptions during a pandemic: gaps identified and lessons learned. J Dent Educ. (2020) 84:12704. doi: 10.1002/jdd.12236

9. Gaudin A, Arbab-Chirani R, Pérez F. Effect of COVID-19 on dental education and practice in France. Front Dent Med. (2020) 1:5. doi: 10.3389/fdmed.2020.00005

10. Meng L, Hua F, Bian Z. Coronavirus disease 2019 (COVID-19): emerging and future challenges for dental and oral medicine. J Dent Res. (2020) 99:4817. doi: $10.1177 / 0022034520914246$

11. Quinn B, Field J, Gorter R, Akota I, Manzanares MC, Paganelli C, et al. COVID-19: the immediate response of european academic dental institutions and future implications for dental education. Eur J Dent Educ. (2020) 24:8114. doi: $10.1111 /$ eje. 12542

12. Wong J, Lee AHC, Zhang C. Effect of COVID-19 on dental education and endodontic practice in Hong Kong. Front Dent Med. (2020) 1:569225. doi: 10.3389/fdmed.2020.5 69225

13. Desai BK. Clinical implications of the COVID-19 pandemic on dental education. J Dent Educ. (2020) 84:512. doi: 10.1002/jdd.12162

14. Iyer P, Aziz K, Ojcius DM. Impact of COVID-19 on dental education in the United States. J Dent Educ. (2020) 84:718-722. doi: 10.1002/jd d. 12163

15. American Dental Association. COVID-19 State Mandates and Recommendations. Chicago, IL: American Dental Association (2020).

16. Centers for Disease Control. Framework for Healthcare Systems Providing Non-COVID-19 Clinical Care During the COVID-19 Pandemic. Atlanta, GA: Centers for Disease Control (2020).

17. Association for Documentary Editing. Response of the Dental Education Community to Novel Coronavirus. Lewes, DE: Association for Documentary Editing (2020).

18. Wu ZY, Zhang ZY, Jiang XQ, Guo L. Comparison of dental education and professional development between mainland China and North America. Eur J Dent Educ. (2010) 14:106-12. doi: 10.1111/j.1600-0579.2009.0 0599.x

19. Haden NK, Hendricson WD, Kassebaum DK, Ranney RR, Weinstein G, Anderson EL, et al. Curriculum change in dental education, 2003-09. J Dent Educ. (2010) 74:539-57. doi: 10.1002/j.0022-0337.2010.74.5.tb04901.x

20. Ling J, Fu Y. Recent changes in the curriculum of Chinese dental schools. $J$ Dent Educ. (2007) 71:1447-56. doi: 10.1002/j.0022-0337.2007.71.11.tb04416.x

21. Komabayashi T, Razak AA, Bird WF. Dental education in Malaysia. Int Dent J. (2007) 57:429-32. doi: 10.1111/j.1875-595X.2007.tb 00145.x

22. Khan FR. A proposed curriculum for 5-years BDS programme in Pakistan and its comparison with the curricula suggested by PMDC and HEC. JPDA. (2020) 29:169-71. doi: 10.25301/JPDA.294.169

23. Sun H, Yang J, Kawashima N, Li Y, Zhang W, Wang P. A brief comparison of curricula at dental schools in China and Japan. J Dent Educ. (2012) 76:765-73. doi: 10.1002/j.0022-0337.2012.76.6.tb05312.x

24. Baqain ZH, Alshalan TA, Naaman N, Faleh S. An overview of dental education in the Arab world. Fac Dent J. (2016) 7:172-4. doi: 10.1308/rcsfdj.2016.172

25. Majeed MM, Durrani MS, Bashir MB, Ahmed M. COVID-19 and dental education in Pakistan. J Coll Physicians Surg Pak. (2020) 30:1157. doi: $10.29271 /$ jcpsp.2020.Supp2.115

26. Rad FA, Otaki F, Baqain Z, Zary N, Al-Halabi M. Rapid transition to distance learning due to COVID-19: perceptions of postgraduate dental learners and instructors. PLoS ONE. (2021) 16:e0246584. doi: 10.1371/journal.pone.0246584

27. American Dental Association. Dental School During a Pandemic. Chicago, IL: American Dental Association (2020).

28. American Dental Association. Going Virtual: Distance Learning Amid COVID-19 Pandemic. Chicago, IL: Ameriscan Dental Association (2020).

29. Council UDS. The Impact of Covid-19 on Dental Education. London: Council UDS (2021).

30. Malaysia MoH. Milestones in Dentistry, Oral Health Programme, (2021).

31. Stoopler ET, Tanaka TI, Sollecito TP. Hospital-based dental externship during COVID-19 pandemic: think virtual! Spec Care Dent. (2020) 40:3934. doi: $10.1111 /$ scd. 12473

32. American Student Dental Association. ASDA's Letter to State Dental Board. Chicago, IL: American Student Dental Association (2020).

33. Ghai S. Teledentistry during COVID-19 pandemic. Diabetes Metab Syndr. (2020) 14:933-5. doi: 10.1016/j.dsx.2020.06.029

34. Ghai S. Are dental schools adequately preparing dental students to face outbreaks of infectious diseases such as COVID-19? J Dent Educ. (2020) 84:631-3. doi: 10.1002/jdd.12174

35. Rosa B, Ferreira MD, Moreira GC, Bastos MF, Pinto RR, Visconti MA, et al. The COVID-19 post-pandemic scenario to oral radiology at dental schools. Oral Radiol. (2020) 36:406-7. doi: 10.1007/s11282-020-00466-7

36. Fontenele RC, Gomes AF, Freitas DQ. Oral radiology practice in dental schools during the COVID-19 pandemic: what will be the new normal? Imaging Sci Dent. (2020) 50:265-7. doi: 10.5624/isd.2020.50.3.265

37. Doriguetto PVT, Americano JP, Devito KL. Challenges for the dental radiology clinic in times of the COVID-19 pandemic. Oral Radiol. (2020) 36:4045. doi: 10.1007/s11282-020-00456-9

38. Long RH, Ward TD, Pruett ME, Coleman JF, Plaisance MC Jr. Modifications of emergency dental clinic protocols to combat COVID-19 transmission. Spec Care Dent. (2020) 40:219-26. doi: 10.1111/scd.12472

39. American Dental Association CoDA. CODA Asks Accredited Dental Programs for Details on COVID-19 Response. Chicago, IL: American Dental Association CoDA (2020). 
40. Fernandez A, Howse E, Rubio-Valera M, Thorncraft K, Noone J, Luu $\mathrm{X}$, et al. Setting-based interventions to promote mental health at the university: a systematic review. Int J Public Health. (2016) 61:797807. doi: 10.1007/s00038-016-0846-4

41. Babar MG, Hasan SS, Ooi YJ, Ahmed SI, Wong PS, MNM-Rosdy NM, et al. Perceived sources of stress among Malaysian dental students. Int J Med Educ. (2015) 6:56-61. doi: 10.5116/ijme.55 $21.3 \mathrm{~b} 2 \mathrm{~d}$

42. Oberoi G, Nitsch S, Edelmayer M, Janjic K, Muller AS, Agis H. 3D printing-encompassing the facets of dentistry. Front Bioeng Biotechnol. (2018) 6:172. doi: 10.3389/fbioe.2018.0 0172

43. Höhne C, Dickhaut N, Schmitter M. Introduction of a new teaching concept for dentin post preparation with 3D printed teeth. Euro J Dent Educ. (2020) 24:499-506. doi: 10.1111/eje.12528
44. Haridy R, Abdalla MA, Kaisarly D, Gezawi ME. A cross-sectional multicenter survey on the future of dental education in the era of COVID-19: alternatives and implications. J Dent Educ. (2020) 85:483-93. doi: 10.1002/jdd.12498

Conflict of Interest: The authors declare that the research was conducted in the absence of any commercial or financial relationships that could be construed as a potential conflict of interest.

Copyright (c) 2021 Alrashdi, Hameed and Aljabr. This is an open-access article distributed under the terms of the Creative Commons Attribution License (CC BY). The use, distribution or reproduction in other forums is permitted, provided the original author(s) and the copyright owner(s) are credited and that the original publication in this journal is cited, in accordance with accepted academic practice. No use, distribution or reproduction is permitted which does not comply with these terms. 